\title{
Introducing the bromide/alkalinity ratio for a follow-up discussion on "Precipitation of salts in freezing seawater and ozone depletion events: a status report", by Morin et al., published in Atmos. Chem. Phys., 8, 7317-7324, 2008
}

\author{
R. Sander ${ }^{1}$ and S. Morin ${ }^{2,3}$ \\ ${ }^{1}$ Air Chemistry Department, Max-Planck Institute of Chemistry, P.O. Box 3060, 55020 Mainz, Germany \\ ${ }^{2}$ Météo-France - CNRS, CNRM/GAME, CEN, 1441, rue de la piscine, 38400 St. Martin d'Hères, France \\ ${ }^{3}$ CNRS - UJF Grenoble, LGGE, 54 rue Molière, 38400 St Martin d'Hères, France
}

Received: 4 August 2009 - Published in Atmos. Chem. Phys. Discuss.: 2 October 2009

Revised: 29 June 2010 - Accepted: 11 August 2010 - Published: 17 August 2010

\begin{abstract}
Sander et al. (2006) proposed that $\mathrm{CaCO}_{3}$ precipitation can be an important factor in triggering tropospheric ozone depletion events. Recently, Morin et al. (2008b) presented calculations with the FREZCHEM model and concluded that their results and interpretation cast doubt on the validity of this hypothesis. In this joint publication, we have re-analyzed the implications of the FREZCHEM results and show how they can be reconciled with the proposal of Sander et al. (2006). The chemical predictions of both approaches are consistent. Although an interpretation solely based on the alkalinity change in the brine does not support the conclusion of Sander et al. (2006), we show that the bromide/alkalinity ratio (which increases during the cooling of the brine) can be used as an indicator of the potential for triggering bromine explosions.
\end{abstract}

\section{Introduction}

Sander et al. (2006) proposed that carbonate precipitation in brine could be a trigger for tropospheric ozone depletion events in polar regions via the following sequence:

1. Cooling of the brine increases its salinity (cryoconcentration).

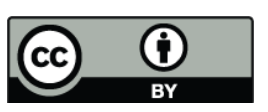

Correspondence to: R. Sander (sander@mpch-mainz.mpg.de)
2. $\mathrm{CaCO}_{3}$ becomes supersaturated and precipitates.

3. The loss of dissolved carbonate (the major contributor to the alkalinity $A_{\mathrm{T}}$ ) reduces the buffering capacity of brine on sea ice.

4. Aerosols resulting from the brine can be acidified more easily.

5. The acid-catalyzed "bromine explosion" produces reactive halogen species (e.g. BrO) in the gas phase.

6. Halogen chemistry leads to tropospheric ozone depletion events.

This mechanism is specific to cold regions (marine boundary layer temperatures sustained below the freezing point of water), and is therefore considered potentially capable of explaining the occurrence of tropospheric ozone depletion events in polar regions. The mechanism does not necessarily have to involve aerosols as suggested in point 4 above. Indeed, any mechanism inducing physical separation of the precipitate and the brine prior to acidification would suffice (see Fig. 1 in Morin et al., 2008b). Sander et al. (2006) supported their proposal with preliminary calculations. However, due to lack of temperature-dependent data, thermodynamic constants at $273 \mathrm{~K}$ had to be used. In addition, activity coefficients were not taken into account. Improved calculations of $\mathrm{CaCO}_{3}$ precipitation were presented by Morin et al. (2008b) to test this hypothesis. The FREZCHEM model was

Published by Copernicus Publications on behalf of the European Geosciences Union. 


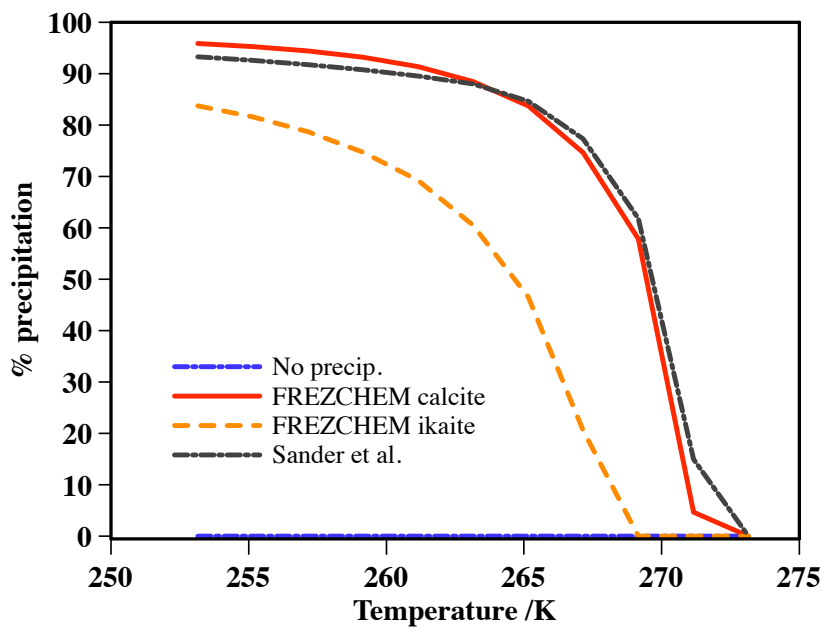

Fig. 1. Precipitation of calcium carbonate during the freezing of sea water.

used which is able to extrapolate thermodynamic constants into the subzero $(T<273 \mathrm{~K})$ temperature range, and explicitly calculates activity coefficients in concentrated solutions (Marion, 2001). After the public discussion of the ACPD paper (Morin et al., 2008a), new information became available showing that out of the polymorphs of $\mathrm{CaCO}_{3}$, ikaite is more likely to precipitate than calcite (Dieckmann et al., 2008). Implementation of ikaite into FREZCHEM led to less carbonate precipitation. Morin et al. (2008b) now concluded that their result "strongly contradicts the predictions of Sander et al. (2006) and casts doubts on the validity of the hypothesis originally described by these authors". In this paper we re-analyze the implications of the FREZCHEM results and show that they can be reconciled with the proposal of Sander et al. (2006).

\section{Discussion}

\subsection{The effect of cooling on the alkalinity of brine (cryoconcentration)}

For a better comparison of the two studies, plots were created that include both the results of Sander et al. (2006) and Morin et al. (2008b). Figure 1 shows the precipitation of calcium carbonate during the freezing of sea water. The black line is the same as that in Fig. 2 of Sander et al. (2006). The red and the orange lines show the FREZCHEM results for calcite and ikaite precipitation, respectively. It can be seen that the preliminary calculations by Sander et al. (2006) are very similar to the FREZCHEM results for calcite precipitation. However, when ikaite is considered, the precipitation of carbonate is substantially lower.

The alkalinity $A_{\mathrm{T}}$ of the brine as a function of temperature is shown in Fig. 2. This plot is similar to Fig. 5 of Morin et al. (2008b) but contains two additional lines: the

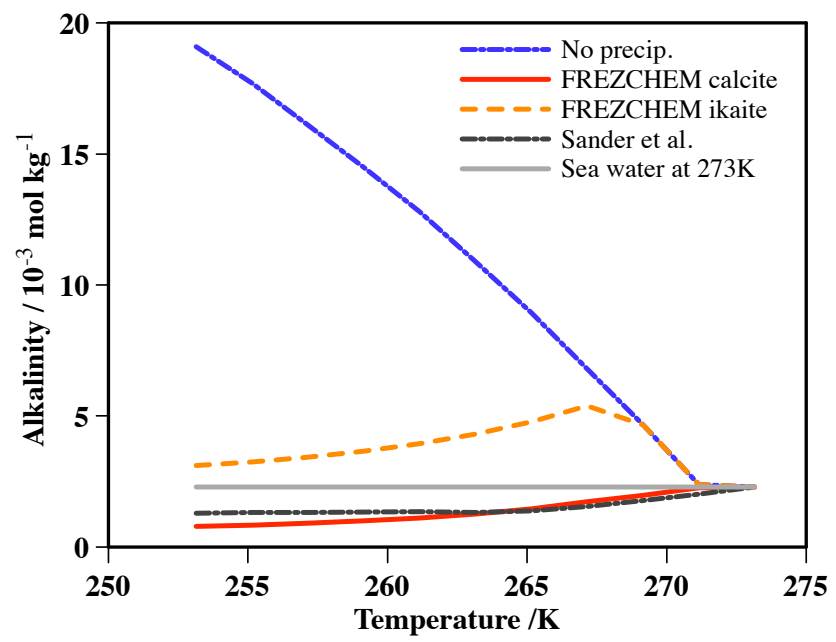

Fig. 2. Alkalinity $A_{\mathrm{T}}$ of the brine during the freezing of sea water. The definition is $A_{\mathrm{T}}=m\left(\mathrm{OH}^{-}\right)+m\left(\mathrm{HCO}_{3}^{-}\right)+2 m\left(\mathrm{CO}_{3}^{2-}\right)+$ $2 m\left(\mathrm{CaCO}_{3}^{\circ}\right)+2 m\left(\mathrm{MgCO}_{3}^{\circ}\right)-m\left(\mathrm{H}^{+}\right)$, where $\mathrm{CaCO}_{3}^{\circ}$ and $\mathrm{MgCO}_{3}^{\circ}$ represent dissolved ion pairs.

blue line shows $A_{\mathrm{T}}$ when carbonate precipitation is artificially switched off, and the grey line shows the alkalinity of sea water at $T=273 \mathrm{~K}$. This figure requires careful interpretation. It shows that although ikaite precipitation removes a substantial fraction of the alkalinity at subzero temperature, $A_{\mathrm{T}}$ of the brine is always above the value for seawater at $273 \mathrm{~K}$. This results from two opposing effects: 1) the alkalinity increases because the brine becomes more concentrated at lower temperatures (cryoconcentration), and 2 ) it decreases due to carbonate precipitation. When ikaite is formed, the precipitation does not completely compensate for the cryoconcentration effect. This led Morin et al. (2008b) to the conclusion that ikaite precipitation in the brine prior to aerosol generation does not deplete the alkalinity of airborne particles (relative to particles produced from unfractionated seawater above freezing), thereby challenging the conclusions of Sander et al. (2006). Indeed, interpreted this way it is difficult to see how the mechanism presented in the introduction can trigger bromine explosions at subzero temperatures.

\subsection{Equilibration with ambient humidity (evapoconcentration)}

Up to this point a surface-borne liquid is considered that can represent e.g. a brine layer possibly covered with frost flowers or brine in salty snow. In the simulations carried out by Sander et al. (2006), it was assumed that bromine explosions occur within brine-derived aerosols. Under such an hypothesis, one has to evaluate what is the chemical composition of aerosols derived from the brine. Once the brine has been injected into the air and formed aerosol particles, $\mathrm{H}_{2} \mathrm{O}$ will evaporate until equilibration with the ambient humidity is 
reached. Long-term observations by Treffeisen et al. (2007) found relative humidities between $\mathrm{RH}=60 \%$ and $\mathrm{RH}=90 \%$ for near-surface air at $\mathrm{Ny}$-Ålesund. Using a typical value of $\mathrm{RH}=80 \%$, a NaCl solution of $m\left(\mathrm{Na}^{+}\right.$(aerosol) $) \approx 5 \mathrm{~mol} / \mathrm{kg}$ is reached (Tang et al., 1997). According to Koop et al. (2000), the deliquescence/efflorescence curves of sea salt hardly depend on temperature, suggesting that the water activity of sea salt solutions of fixed molality also remains nearly constant with changes in temperature. Thus, like Sander et al. (2006), we assume a $\mathrm{NaCl}$ molality of $5 \mathrm{~mol} / \mathrm{kg}$ in aerosol particles for $\mathrm{RH}=80 \%$ at all temperatures.

This vaporization leads to an increase of the concentrations of all solutes (evapoconcentration). The evaporation factor $f_{\text {evap }}$ describes the molality ratio before and after evaporation:

$f_{\text {evap }}=\frac{m\left(\mathrm{Na}^{+}(\text {aerosol })\right)}{m\left(\mathrm{Na}^{+}(\text {brine })\right)}$

The process of evapoconcentration is visualized in Fig. 3 for different temperatures. Red squares denote the molality of $\mathrm{Na}^{+}$in brine (after cryoconcentration), and red circles show the molality in the aerosol (after evapoconcentration). Since cryoconcentration brings the $\mathrm{Na}^{+}$molality closer to its final value of $5 \mathrm{~mol} / \mathrm{kg}, f_{\text {evap }}$ is smaller at lower temperatures.

Evapoconcentration increases the molality of all solutes equally, thus the same factor $f_{\text {evap }}$ can be applied to the alkalinity $A_{\mathrm{T}}$ :

$A_{\mathrm{T}}($ aerosol $)=A_{\mathrm{T}}($ brine $) \times \frac{m\left(\mathrm{Na}^{+}(\text {aerosol })\right)}{m\left(\mathrm{Na}^{+}(\text {brine })\right)}$

The black squares in Fig. 3 show the brine alkalinity from the FREZCHEM ikaite model simulation (same as orange line in Fig. 2). The black circles show the aerosol alkalinity after evapoconcentration. It can be seen that it decreases with decreasing temperature. Thus, aerosols generated at low temperature contain less alkalinity even though they were generated from brine with an alkalinity higher than that of seawater at $273 \mathrm{~K}$. Below $266 \mathrm{~K}$, evapoconcentration always leads to aerosol alkalinities below $15 \mathrm{mmol} \mathrm{kg}^{-1}$ used by Sander et al. (2006). Even taking into account the evapoconcentration of alkalinity in airborne aerosols, the situation modeled by Sander et al. (2006) seems to be rather conservative in terms of the alkalinity of aerosols (aerosol alkalinities are rather on the order of $5 \mathrm{mmol} \mathrm{kg}^{-1}$ at temperatures around $255 \mathrm{~K}$, i.e. one third of the initial alkalinity used by Sander et al. (2006) in their model study).

\subsection{Introducing the $m\left(\mathrm{Br}^{-}\right) / A_{\mathrm{T}}$ ratio}

Rather than computing $A_{\mathrm{T}}$ in aerosol formed from brine as a function of only the $\mathrm{Na}^{+}$concentration in the brine, we

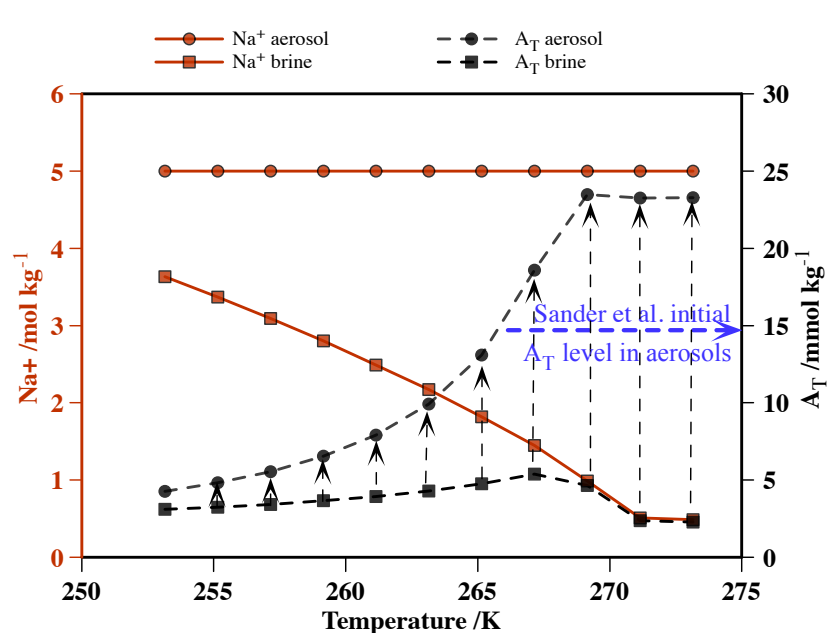

Fig. 3. $A_{\mathrm{T}}$ (black, dashed) and $\mathrm{Na}^{+}$(red, solid) molalities in brine (squares, "cryoconcentrated") and in aerosols (circles, "evapoconcentrated") as a function of temperature. A Na ${ }^{+}$molality of 5 mol kg-1 was used. The "evapoconcentration" curve for $A_{\mathrm{T}}$ can be directly compared to the $A_{\mathrm{T}}$ value chosen by Sander et al. (2006) to initialize their model runs in the case where carbonate precipitation is allowed, which is presented in blue. Vertical dashed arrows illustrate $A_{\mathrm{T}}$ evapoconcentration pathways.

propose to also take into account the bromide concentration in the brine. Thus, Eq. (2) can be rewritten as:

$A_{\mathrm{T}}($ aerosol $)=\frac{\left(\frac{\left.m\left(\mathrm{Br}^{-} \text {(brine }\right)\right)}{m\left(\mathrm{Na}^{+}(\text {brine })\right)}\right) \times m\left(\mathrm{Na}^{+}(\text {aerosol })\right)}{\left(\frac{\left.m\left(\mathrm{Br}^{-} \text {(brine }\right)\right)}{A_{\mathrm{T}}(\text { brine })}\right)}$

The first term in the numerator describes the seawater ratio of $\mathrm{Br}^{-} / \mathrm{Na}^{+}$which is constant as long as no significant precipitation occurs for either sodium or bromide (bromide is one of the most soluble ions in sea water during freezing, it does not precipitate into any crystalline form within the temperature range considered here, Morin et al., 2008b). The second term is also constant when a $\mathrm{Na}^{+}$molality of $5 \mathrm{~mol} \mathrm{~kg}^{-1}$ is used. Thus Eq. (3) shows that the aerosol alkalinity is inversely proportional to the ratio $m\left(\mathrm{Br}^{-}\right) / A_{\mathrm{T}}$.

It is clear that the acid-catalyzed bromine explosion can only occur if the available acidity is larger than $A_{\mathrm{T}}$. However, since bromide and acidity are both needed for bromine explosions, it is the ratio $m\left(\mathrm{Br}^{-}\right) / A_{\mathrm{T}}$ that determines how much bromine can be liberated from the solution once a certain amount of alkalinity has been neutralized. It can be considered representative of the potential for triggering bromine explosions. While cryoconcentration of the alkalinity is reduced due to carbonate precipitation, the molality of highly soluble $\mathrm{Br}^{-}$increases considerably during freezing (Morin et al., 2008b). Note that this calculation would be similar using soluble ions other than bromide. Our choice is motivated here by the relevance of the bromide ion to the bromine explosion mechanism. 


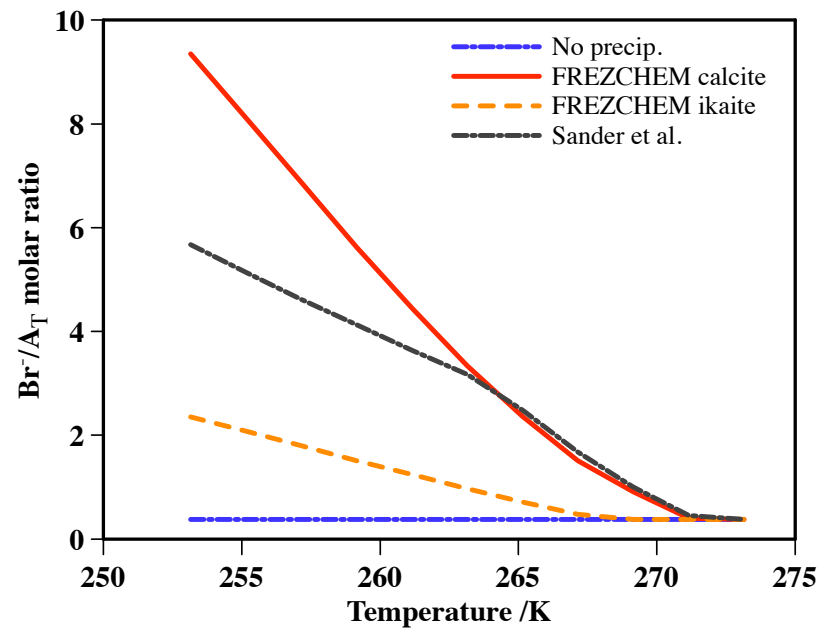

Fig. 4. The ratio of bromide to alkalinity during the freezing of sea water.

Figure 4 shows how $m\left(\mathrm{Br}^{-}\right) / A_{\mathrm{T}}$ increases with decreasing temperature for both, calcite and ikaite precipitation. In the case where ikaite is set to precipitate in the FREZCHEM run, this increase is lower than for calcite, and also starts to increase at lower temperatures. Thus the temperature at which the brine is separated from the precipitate is critical. Nevertheless, the strong temperature dependence of this ratio makes this a possible explanation of the fact that ozone depletion events are mainly found in cold regions. This approach reconciles the results of Sander et al. (2006) and Morin et al. (2008b). Also, observations are now available showing that ikaite precipitation occurs in the Arctic (Dieckmann et al., 2010) as well as in the Antarctic (Dieckmann et al., 2008). It should be noted though, that all results and discussions presented here assume thermodynamic equilibrium. For future studies, the kinetics of precipitation and dissolution should also be taken into account, a topic which is mentioned in Marion et al. (2009).

\section{Conclusions}

A re-analysis of the FREZCHEM calculations by Morin et al. (2008b) has shown that, although ikaite precipitation is less efficiently removing carbonate than calcite precipitation, these results do not contradict the proposal of Sander et al. (2006), as long as the interpretation of the results is based on the $m\left(\mathrm{Br}^{-}\right) / A_{\mathrm{T}}$ ratio and not just on the alkalinity of the medium where bromine activation occurs.
Acknowledgements. We would like to thank J. Burrows, R. von Glasow, L. Kaleschke, T. Koop, G. Marion, D. Voisin, and E. Wolff for very helpful suggestions and discussions.

The service charges for this open access publication have been covered by the Max Planck Society.

Edited by: T. Koop

\section{References}

Dieckmann, G. S., Nehrke, G., Papadimitriou, S., Göttlicher, J., Steininger, R., Kennedy, H., Wolf-Gladrow, D., and Thomas, D. N.: Calcium carbonate as ikaite crystals in Antarctic sea ice, Geophys. Res. Lett., 35, L08501, doi:10.1029/2008GL033540, 2008.

Dieckmann, G. S., Nehrke, G., Uhlig, C., Göttlicher, J., Gerland, S., Granskog, M. A., and Thomas, D. N.: Brief Communication: Ikaite $\left(\mathrm{CaCO}_{3} \cdot 6 \mathrm{H}_{2} \mathrm{O}\right)$ discovered in Arctic sea ice, The Cryosphere, 4, 227-230, doi:10.5194/tc-4-227-2010, 2010.

Koop, T., Kapilashrami, A., Molina, L. T., and Molina, M. J.: Phase transitions of sea-salt/water mixtures at low temperatures: Implications for ozone chemistry in the polar marine boundary layer, J. Geophys. Res., 105D, 26393-26402, 2000.

Marion, G. M.: Carbonate mineral solubility at low temperatures in the Na-K-Mg-Ca-H-Cl-SO $4-\mathrm{OH}-\mathrm{HCO}_{3}-\mathrm{CO}_{3}-\mathrm{CO}_{2}-\mathrm{H}_{2} \mathrm{O}$ system, Geochim. Cosmochim. Acta, 65, 1883-1896, 2001.

Marion, G. M., Millero, F. J., and Feistel, R.: Precipitation of solid phase calcium carbonates and their effect on application of seawater $S_{A}-T-P$ models, Ocean Sci., 5, 285-291, doi:10.5194/os5-285-2009, 2009.

Morin, S., Marion, G. M., von Glasow, R., Voisin, D., Bouchez, J., and Savarino, J.: Precipitation of salts in freezing seawater and ozone depletion events: a status report, Atmos. Chem. Phys. Discuss., 8, 9035-9060, doi:10.5194/acpd-8-9035-2008, 2008a.

Morin, S., Marion, G. M., von Glasow, R., Voisin, D., Bouchez, J., and Savarino, J.: Precipitation of salts in freezing seawater and ozone depletion events: a status report, Atmos. Chem. Phys., 8, 7317-7324, doi:10.5194/acp-8-7317-2008, 2008b.

Sander, R., Burrows, J., and Kaleschke, L.: Carbonate precipitation in brine - a potential trigger for tropospheric ozone depletion events, Atmos. Chem. Phys., 6, 4653-4658, doi:10.5194/acp-64653-2006, 2006.

Tang, I. N., Tridico, A. C., and Fung, K. H.: Thermodynamic and optical properties of sea salt aerosols, J. Geophys. Res., 102D, 23269-23275, 1997.

Treffeisen, R., Krejci, R., Ström, J., Engvall, A. C., Herber, A., and Thomason, L.: Humidity observations in the Arctic troposphere over Ny-Ålesund, Svalbard based on 15 years of radiosonde data, Atmos. Chem. Phys., 7, 2721-2732, doi:10.5194/acp-7-27212007, 2007. 